\title{
Giant Cell Tumor of Tendon Sheath of the Hand: Experience With Forty- Seven Cases
}

\author{
Davod Jafari ${ }^{1}$; Hooman Shariatzadeh ${ }^{1}$; Farid Najd Mazhar ${ }^{1}$; Mehran Razavipour ${ }^{1, *}$; \\ Mohammad Ali Okhovatpour ${ }^{1}$ \\ ${ }^{1}$ Bone and Joint Reconstruction Research Center, Shafa Orthopedic Hospital, Iran University of Medical Sciences, Tehran, IR Iran \\ *Corresponding author: Mehran Razavipour, Bone and Joint Reconstruction Research Center, Shafa Orthopedic Hospital, Iran University of Medical Sciences, Tehran, IR Iran. Tel: +98- \\ 2133542041, Fax: +98-2133542042, E-mail: razavimehran@yahoo.com
}

Received: January 11, 2014; Revised: June 3, 2014; Accepted: June 5, 2014

\begin{abstract}
Background: Giant cell tumor of the tendon sheath (GCTTS) is the most common benign tumor of the hand following the ganglion cyst. It is more prevalent in women in third through fifth decades of life.

Objectives: The aim of the study was to investigate the demographic and clinical characteristics as well as the rate of recurrence of GCTTS in an Iranian population.

Patients and Methods: Medical records of 47 patients with GCTTS were reviewed. Data on demographic characteristics as well as clinical and intraoperative findings were collected. Plain X-rays, magnetic resonance, and ultrasonographic images were observed. Patients were asked about the recurrence of the GCTTS after mean interval of $4.9 \pm 2.6$ years.

Results: Females were predominantly involved (70.2\%). Patients aged $38.5 \pm 16.2$ years at the time of surgery. The middle finger was the most common site of the lesion (27.6\%) followed by index finger (25.5\%) and thumb (21.3\%). The volume of the lesions averaged $3.9 \pm 5.5 \mathrm{~cm}^{3}$. The GCTTS had invaded the skin (1 patient), bone (1 patient), tendon pulley (6 patients), tendon (4 patients), and digital nerve ( 2 patients). Osseous erosion was found in two patients. After exact excision, the tumor recurred in four patients (8.5\%). None of the variables affected the risk of recurrence.

Conclusions: The characteristics of our patients were greatly similar to the previous studies. Exact and complete excision of the lesion under magnification was the keystone of decreased rate of GCTTS recurrence.
\end{abstract}

Keywords: Giant Cell Tumor; Tendon Sheath; Benign Tumor; Hand

\section{Background}

Giant cell tumor of the tendon sheath (GCTTS), a solitary benign soft-tissue tumor, is the second most common tumor involving the hand after the ganglions (1, 2). GCTTS may occur at any age but usually presents between third to fifth decades of life and is more prevalent in women (1-6).

Lack of knowledge about the exact etiology and pathogenesis of the lesion resulted in introducing several names for the lesion including nodular tenosynovitis, localized pigmented villonodular synovitis, fibrous xanthoma, fibrous histiocytoma of the synovium, tenosynovial giant cell tumor, benign synovioma, and sclerosing hemangioma, each of which describes a specific feature of the tumor $(1,2,4,7,8)$. The GCTTS is usually painless and grows slowly (5). The lesion is histopathologically distinguished by proliferative synovial-like, giant, inflammatory, and xanthoma cells and siderophages (9). Some authors believe that GCTTS is a neoplastic tumor while others suggested inflammatory, traumatic, or autoimmune nature for the lesion $(1,2)$. In addition, abnormal lipid metabolism has been suggested to be involved in
GCTTS $(1,2)$. Despite the benign nature, local recurrence after excision, with the rate of $4.2 \%$ to $28.6 \%$, has been widely reported $(1,2,4-6,10-12)$. Although radiotherapy can reduce the rate of recurrence (4), recurrent tumors have remained a challenging problem for the hand surgeons. Some factors may predict the recurrence of GCTTS (13); however, the problem to remains unsolved due to our limited knowledge on the nature of the lesion. Therefore, it seems crucial to investigate the clinical, radiologic, and histopathologic characteristics of the tumor to improve our understanding of the problem. Although several studies reported some series of patients with GCTTS $(1,2$, $4-6,11,12,14,15)$, they were insufficient and more reports on the issue are required. Furthermore, there is no report on the treatment of these cases in Iranian population.

\section{Objectives}

The current study aimed to investigate the demographic and clinical characteristics of the patients with GCTTS of the hand as well as the rate and potential risk factors of recurrence. 
Figure 1. Plain X-Ray Images of the Middle Phalanx of the Long Finger

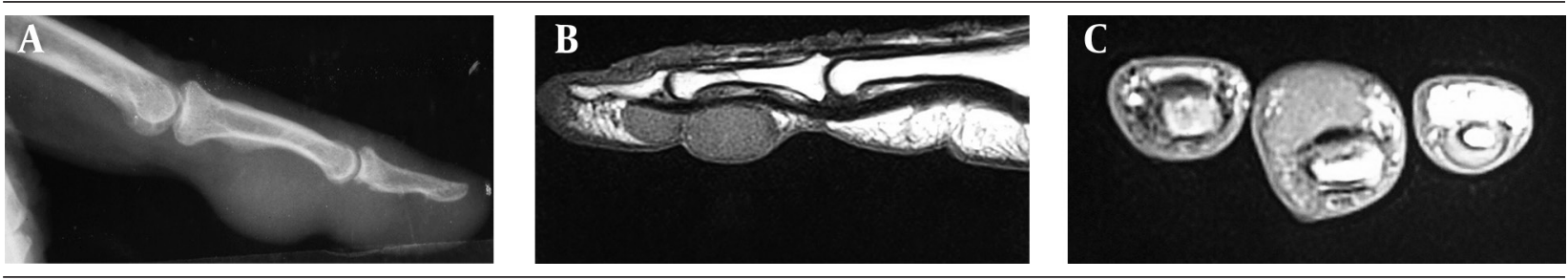

A, Lateral X-ray showing a mass at the volar aspect of the middle phalanx without bony involvement. B and C, Magnetic resonance images of the same lesion in sagittal and axial view showing a hyposignal mass in T1 sequence.

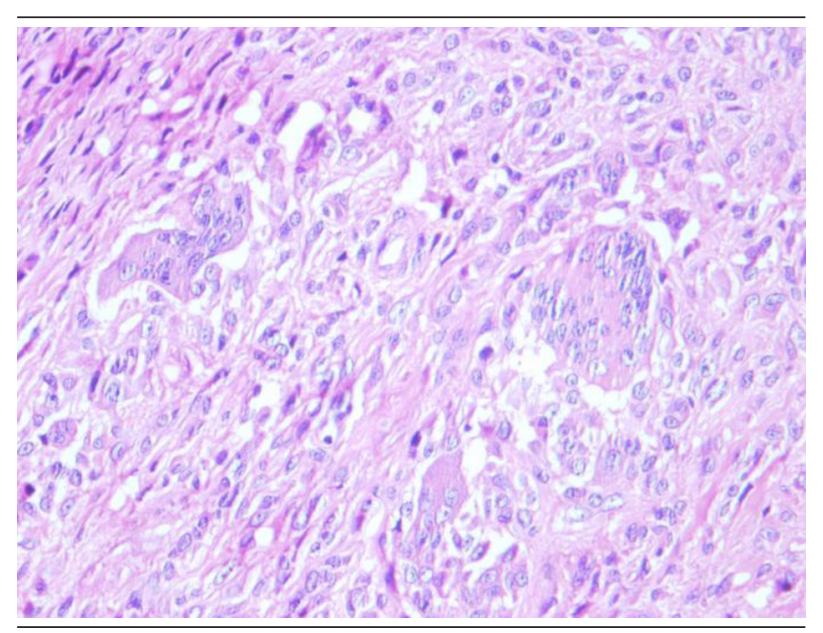

Figure 2. The Microscopic View of the Giant Cell Tumor of The Tendon Sheath Showing Sheets of Small, Histiocyte-Like, Rounded or Polygonal Mononuclear Cells and Larger Epithelioid Mononuclear Cells With Varying Numbers of Osteoclast-Like Giant Cells (Hematoxylin and Eosin Staining; Magnification, (10x)

\section{Patients and Methods}

In this retrospective study, we reviewed the medical records of the patients who had undergone operation for the hand lesions diagnosed as GCTTS between 2000 and 2012. The institutional review board approved the study protocol.

Preoperative physical examinations and hand X-ray images were reviewed (Figure $1 \mathrm{~A}$ ). Ultrasonography or magnetic resonance imaging (MRI) had been utilized for further investigation (Figure 1 B and $1 \mathrm{C}$ ). Three expert hand surgeons had performed all of the surgeries. Loup magnification had been used in all of the surgeries. The diagnosis had been confirmed histopathologically (Figure 2 ). The data regarding the age at surgery, sex, site of the lesion, clinical presentations, time interval between onset of symptoms and surgery, intraoperatively-confirmed involvement of bone, joint, tendon or neurovascular bundles, the size of the tumor based on the histopathologic report, histopathologic findings, and recurrence of the lesion were gathered. The patients were contacted via telephone and were asked to attend the hospital for examination. Some patients, who did not attend the hospital, were followed up by phone. Patients were followed up for $4.9 \pm 2.6$ years (range, 2-12 years).

\subsection{Statistics}

The correlation between recurrence and measured variables was investigated utilizing Pearson's correlation coefficient ( $r$ ) for quantitative variables or Spearman's rank correlation coefficient (rho) for qualitative variables. In addition, the linear regression analysis was performed to determine the risk factors of tumor recurrence. Statistical analysis was performed with SPSS 15.0 (SPSS Inc, Chicago, Illinois, the United States). P value $<0.05$ was considered statistically significant.

\section{Results}

A total of 54 patients had undergone surgical excision of GCCTS in Shafa Orthopedic Hospital, Tehran, Iran; during 2002-2012. Seven patients were lost to follow-up and the study was completed on the remaining 47 . There were 14 males (29.8\%) and 33 females (70.2\%) aged $38.5 \pm 16.2$ years. The right and left hand was involved in 27 (57.4\%) and 20 patients (42.6\%), respectively. Ten patients had undergone surgical excision of the GCTTS at the same site previously. The surgeries were performed after $2.3 \pm 1.9$ years of symptoms onset (range, 2.5 months to 7 years). The middle finger was predominantly involved (13 patients, $27.6 \%$ ) followed by index finger (12 patients, $25.5 \%)$ and thumb (10 patients, 21.3\%). The ring and little fingers and wrist, each were involved in four patients (8.5\%). Among the patients with finger involvement (43 patients), the middle phalanx was the most common site of GCTTS growth (19 patients, $44.2 \%$ ) followed by proximal phalanx (15 patients, $34.9 \%$ ). The distal phalanx was involved in five patients. The GCTTS of thumb interphalangeal and metacarpophalangeal and proximal interphalangeal joints of other fingers were found each in two patients. Distal interphalangeal (DIP) joint was involved only in one patient. Of these, three patients had satellite lesion involving proximal and distal phalanxes (one patient), thumb interphalangeal with thumb distal phalanx (one patient), and DIP and distal phalanx (one patient). The mean volume of the lesions was $3.9 \pm 5.5 \mathrm{~cm}^{3}$ (range, $0.13-27 \mathrm{~cm}^{3}$ ).

Intraoperatively, we found that the GCTTS had invaded the skin in one patient; the tendon in four, tendon pulley in six, and digital nerve in two. In addition, osseous erosion was seen in two patients. The tendon and joint were involved in one patient and nerve and bone in another one. 
Jafari D et al.

\begin{tabular}{|c|c|c|c|c|c|c|}
\hline Sex & Age, $y$ & Site of Lesion & $\begin{array}{l}\text { Invasion to the Sur- } \\
\text { rounding Tissue }\end{array}$ & $\begin{array}{l}\text { Volume of the } \\
\text { Tumor, } \mathbf{c m}^{3}\end{array}$ & $\begin{array}{l}\text { Interval Between } \\
\text { Surgery and Re- } \\
\text { currence, } y\end{array}$ & Comments \\
\hline Female & 36 & $\begin{array}{l}\text { Radial side of proximal } \\
\text { interphalangeal joint of } \\
\text { the 3rd finger }\end{array}$ & Not found & 3 & 2 & $\begin{array}{l}\text { The patient was oper- } \\
\text { ated on for the second } \\
\text { time. }\end{array}$ \\
\hline Male & 70 & $\begin{array}{l}\text { Volar side of middle pha- } \\
\text { lanx of the 3rd finger }\end{array}$ & Skin & 17.5 & 2 & - \\
\hline Male & 18 & $\begin{array}{l}\text { Volar side of proximal } \\
\text { phalanx of the } 4 \text { th finger }\end{array}$ & Not found & 18 & 1 & - \\
\hline Female & 21 & $\begin{array}{l}\text { Volar side of middle pha- } \\
\text { lanx of the } 4 \text { th finger }\end{array}$ & Bone & 10 & 2 & $\begin{array}{l}\text { The patient was oper- } \\
\text { ated on for second } \\
\text { time. }\end{array}$ \\
\hline
\end{tabular}

In follow-up, we found that the lesion was recurred in four patients. Two of these patients were operated for recurrent GCTTS. The characteristics of these four patients are presented in Table 1 . We found no significant correlation between recurrence of GCTTS and other variables such as previous history of surgery or invasion to other tissues. The histopathologic findings did not differ between patients with and without recurrence. In addition, the regression analysis showed that none of the variables had association with the recurrence of the GCTTS.

\section{Discussion}

The GCTTS is most commonly found in the hand region $(77 \%-92.9 \%)(6,16,17)$. The GCTTS of the hand is a painless slow-growing mass and many patients only complain of a swelling mass more often located at the palmar surface $(1,2,4,10,11,14)$. In current study, none of the patients had explained pain. In most of the previous studies, hand GCTTS was predominantly found in females $(1,2,4-6,11,12$, $14,15)$. Moreover, Women were predominantly involved in our study (male to female ratio, 1:2). However, Gholve et al. found slight male predominance (14).

In other studies, some differences in term of age distribution were reported, but in many of them, patients were at any age with a peak involvement at third to fifth decades of life $(1,5,6,11)$. Similar to previous studies, our patients were at any age and most of them were in fourth decade of their life (34\%). The GCTTS involves the index finger in most of the patients followed by middle finger or thumb $(1,6,10)$; in our study, however, the middle finger was the most common site of involvement. Di Grazia et al. (5), Garg and Kotwal (4), and Darwish and Haddad (2) found that the incidence of GCTTS was highest in middle finger, ring finger and thumb, consecutively. In addition, in our study, the frequency of index finger or thumb involvement was close to that of the middle finger with a little difference.

The most concerning problem in treatment of patients with GCTTS arises from high rate of lesion recurrence reported from $4.2 \%$ to $28.6 \%$ (1, 2, 4-6, 10-12). Despite other studies, the recurrence rate in our study was low (8.5\%) suggesting that the cornerstone of preventing GCTTS recurrence is exact and complete removal of the lesion with optimal surgical technique under magnification and with great expertise. Several authors believe that meticulous, complete excision of the GCTTS is the best way to prevent the recurrence $(1,3,5,6,14)$. Poor surgical technique and inappropriate exposure lead to incomplete removal of the lesion and increased recurrence rate. Ozalp et al. showed that optimal surgical exposure and magnification are important factors regarding achieving satisfactory outcomes (3).

In some cases, GCTTS spreads around the other structures such as digital nerves and vessels, which significantly complicates complete lesion removal and can increase the risk of recurrence $(2,18,19)$. It necessitates the surgeon to exactly know the geographical pattern of the lesion utilizing imaging studies including MRI and ultrasonographic examination. In addition to routine plain radiography, our patients had been preoperatively examined by MRI or ultrasonography.

Several risk factors have been reported to increase the risk of GCTTS recurrence including adjacent degenerative joint, proximity to distal interphalangeal joints of fingers and interphalangeal joint of the thumb, radiologic osseous erosion, and some histopathologic findings such as types of cells, increased cellularity or mitotic activity, capsular involvement, and 23-nm negativity (1, $2,11,14)$. Recently, Al-Qattan et al. demonstrated that the risk of recurrence is greater in tumors surrounded by pseudocapsule (1). Moreover, Williams et al. suggested that direct involvement of flexor or extensor tendons or involvement of the joint capsule increases the risk of recurrence (12). However, we could not detect any correlation between above-mentioned factors and recurrence of the tumor in present study because of the few numbers of recurrent lesions.

Invasion to adjacent tissues (tendon or tendon pulley, bone, nerve, skin, and joint) was found in up to one-third of our patients; however, osseous involvement was found only in tow patients. The GCTTS had recurred in one of these two cases. Although there was no significant find- 
ing in our study, this may indicate that the intraosseous involvement can be considered as an important predictive variable for recurrence of GCTTS. The true intraosseous involvement is rarely reported (20-23). Uriburu and Levy found that the lesion recurred in two of 15 patients with bony involvement (23).

In some patients, the long-standing pressure from slowgrowing tumor makes a little bony concavity without any true bony invasion and consequent increased the risk of recurrence. Bony erosion due to the pressure from the slowly growing tumor has been found in $4.7 \%-25 \%$ of patients $(1,2,4,10,11,24,25)$. Al-Qattan et al. also found eight patients with bony indentation due to the pressure and explained that it should not be considered as intraosseous invasion (1). Another patient with recurrent lesion had skin involvement, which had not not reported as a risk factor in previous surgeries.

In our study, two of four patients with recurrent lesions had a history of previous surgical excision of GCTTS in other hospitals; moreover, it was impossible to excise the tumor completely because of the effects of previous surgery and extensive tumor spreads. Similar to other studies, there were some limitations to the current study. Our study was limited by its retrospective design. In addition, we did not investigate the histopathologic features of the tumors and the correlation of these findings with the risk of recurrence.

In conclusion, the demographic and clinical findings of our patients were highly consistent with those described in previous studies. Females were predominantly involved. The peak incidence was found in fourth decade of life. The middle finger was the most common site of lesion followed by index finger and thumb. The recurrence rate of GCTTS in our patients was $8.5 \%$. The meticulous and complete surgical excision of the tumor under magnification by expert hand may be the most important factor to decrease the rate of recurrence.

\section{Authors' Contributions}

Study concept and design: Davod Jafari, Farid Najd Mazhar, and Mehran Razavipour. Analysis and interpretation of data: Hooman Shariatzadeh, Mehran Razavipour, and Mohammad Ali Okhovatpour. Drafting the manuscript: Davod Jafari, Hooman Shariatzadeh, Farid Najd Mazhar, Mehran Razavipour, and Mohammad Ali Okhovatpour. Critical revision of the manuscript for important intellectual content: Hooman Shariatzadeh, Farid Najd Mazhar, and Mehran Razavipour. Study supervision: Davod Jafari and Farid Najd Mazhar.

\section{References}

1. Al-Qattan MM. Giant cell tumours of tendon sheath: classification and recurrence rate. J Hand Surg Br. 2001;26(1):72-5.
2. Darwish FM, Haddad WH. Giant cell tumour of tendon sheath: experience with 52 cases. Singapore Med J. 2008;49(11):879-82.

3. Ozalp T, Yercan H, Kurt C, Ozdemir O, Coskunol E. [Giantcell tumors of the tendon sheath involving the hand or the wrist: an analysis of 141 patients]. Acta Orthop Traumatol Turc. 2004;38(2):120-4.

4. Garg B, Kotwal PP. Giant cell tumor of the tendon sheath of the hand. J Orthop Surg . 2011;19(2):218-2120.

5. Di Grazia S, Succi G, Fragetta F, Perrotta RE. Giant cell tumor of tendon sheath: study of 64 cases and review of literature. G Chir. 2013;34(5-6):149-52.

6. Monaghan H, Salter DM, Al-Nafussi A. Giant cell tumour of tendon sheath (localised nodular tenosynovitis): clinicopathological features of 71 cases. J Clin Pathol. 2001;54(5):404-7.

7. Coroneos CJ, O'Sullivan B, Ferguson PC, Chung PW, Anastakis DJ. Radiation therapy for infiltrative giant cell tumor of the tendon sheath. J Hand Surg Am. 2012;37(4):775-82.

8. Ho CY, Maleki Z. Giant cell tumor of tendon sheath: cytomorphologic and radiologic findings in 41 patients. Diagn Cytopathol. 2012;40 Suppl 2:E94-8.

9. Weiss SW, Goldblum JR. Benign Tumors and Tumor-like Lesions of Synovial Tissue. 4th edMissouri: Mosby; 2001.

10. Jalgaonkar A, Dhinsa B, Cottam H, Mani G. Giant cell tumours of tendon sheath of hand: causes and strategies to prevent recurrence. Hand Surg. 2011;16(2):149-54.

11. Hamdi MF, Touati B, Zakhama A. Giant cell tumour of the flexor tendon sheath of the hand: analysis of 27 cases. Musculoskelet Surg. 2012;96(1):29-33.

12. Williams J, Hodari A, Janevski P, Siddiqui A. Recurrence of giant cell tumors in the hand: a prospective study. J Hand Surg Am. 2010;35(3):451-6.

13. Lanzinger WD, Bindra R. Giant cell tumor of the tendon sheath. $J$ Hand Surg Am. 2013;38(1):154-7.

14. Gholve PA, Hosalkar HS, Kreiger PA, Dormans JP. Giant cell tumor of tendon sheath: largest single series in children. J Pediatr Orthop. 2007;27(1):67-74.

15. Zhang Y, Huang J, Ma X, Wang X, Zhang C, Chen L. Giant cell tumor of the tendon sheath in the foot and ankle: case series and review of the literature. J Foot Ankle Surg. 2013;52(1):24-7.

16. Jones FE, Soule EH, Coventry MB. Fibrous xanthoma of synovium (giant-cell tumor of tendon sheath, pigmented nodular synovitis). A study of one hundred and eighteen cases.J Bone Joint Surg Am.1969;51(1):76-86.

17. Ushijima M, Hashimoto H, Tsuneyoshi M, Enjoji M. Giant cell tumor of the tendon sheath (nodular tenosynovitis). A study of 207 cases to compare the large joint group with the common digit group. Cancer. 1986;57(4):875-84.

18. Messoudi A, Fnini S, Labsaili N, Ghrib S, Rafai M, Largab A. [Giant cell tumors of the tendon sheath of the hand: 32 cases]. Chir Main. 2007;26(3):165-9.

19. Lorea P, Medina J, Navarro R, Foucher G. [Recurrence of finger tendon giant cell tumors after excision through a "shark teeth" approach. Report of 25 cases]. Ann Chir Plast Esthet. 2001;46(6):607-10.

20. Booth KC, Campbell GS, Chase DR. Giant cell tumor of tendon sheath with intraosseous invasion: a case report. J Hand Surg Am. 1995;20(6):1000-2.

21. Davis S, Lawton G, Lowy M. Pigmented villo-nodular synovitis: bone involvement of the fingers. Clin Radiol.1975;26(3):357-61.

22. Scott PM. Bone lesions in pigmented villonodular synovitis. Bone Joint Surg Br. 1968;50(2):306-11.

23. Uriburu IJ, Levy VD. Intraosseous growth of giant cell tumors of the tendon sheath (localized nodular tenosynovitis) of the digits: report of 15 cases. J Hand Surg Am. 1998;23(4):732-6.

24. Rao AS, Vigorita VJ. Pigmented villonodular synovitis (giant-cell tumor of the tendon sheath and synovial membrane). A review of eighty-one cases.J Bone Joint Surg Am. 1984;66(1):76-94.

25. Reilly KE, Stern PJ, Dale JA. Recurrent giant cell tumors of the tendon sheath. J Hand Surg Am. 1999;24(6):1298-302. 